\title{
Elastic properties of muscles measured at the elbow in man: II. Patients with Parkinsonian rigidity
}

\author{
RAY L WATTS,* ALLEN W WIEGNER, ROBERT R YOUNG \\ From the Clinical Neurophysiology Laboratory and Neurology Service, Massachusetts General Hospital and \\ Harvard Medical School, Boston, USA
}

SUMMARY A method is described to measure reproducibly stiffness, and therefore "tone", at the elbow of patients with Parkinson's disease using a torque motor. In Parkinsonian versus normal patients (previously reported) it was observed that: (1) the neutral angle in Parkinson's disease patients was significantly smaller $\left(92^{\circ} \pm 15^{\circ}\right)$ than in normals $\left(107^{\circ} \pm 10^{\circ}\right)$, and $(2)$ in Parkinson's disease patients, even with relatively mild symptoms, the upper limb was stiffer than normals in the totally relaxed state with no electromyographic activity present. Our results suggest that changes in the passive mechanical properties of the upper limb affected by Parkinsonian rigidity may have taken place, accounting for the more flexed neutral elbow angle and greater passive stiffness. Using this technique, response to antirigidity therapy and natural progression of illness can be quantitatively assessed and followed.

Parkinsonian rigidity is relatively easily recognised but not well understood. In its purest form, it is a hallmark of Parkinson's disease, but "cogwheel" or "plastic" rigidity may be seen in other neurological illnesses as well. We undertook the present study with two major goals: (1) to develop a simple, reproducible, quantitative measure of "stiffness", and therefore "tone" (or resistance to passive stretch) in the upper extremity of Parkinsonian patients, and (2) to assess the role that possible changes in passive elastic properties in the upper limb affected by the symptoms of parkinsonism may play in the perceived state of pathologically increased "tone".

Clinicians generally use a scale of $1+$ (mild) to $4+$ (very severe) or a descriptive rating of mild, moderate, or severe to characterise rigidity. These scales are somewhat variable from examiner to examiner, may not be as reproducible as one would like, and are relatively insensitive, particularly near the lower end of the range (that is, $1+$ or mild). As Schwab noted, ${ }^{1}$ "it is exceedingly difficult to obtain by routine clinical

Address for reprint requests: Allen W Wiegner, Clinical Neurophysiology Laboratory, Massachusetts General Hospital, Boston, Mass 02114, USA.

Received 2 July 1985 and in revised form 9 December 1985. Accepted 15 December 1985 examination a specific value for rigidity at a given time for comparison with rigidity in the same joint at another time - a requisite for evaluating precisely the effect of an antirigidity medication or of physiotherapy directed against the rigidity."

Webster ${ }^{2-4}$ developed a method which uses the net work required to passively flex and extend a patient's forearm through a $100^{\circ}$ arc at a constant velocity by a servomotor as a measure of rigidity. This work value is obtained by integrating the resistance torque over a complete cycle of flexion and extension. However, in so doing the work performed against the passive elastic load of muscles and connective tissues is subtracted out, thus leaving only the work done by patterned electromyographic discharges of the muscles. Hence, the technique evaluates only the "active" component of hypertonicity. In Lakie, Walsh and Wright's recent study of muscle tone in man utilising the resonant frequency of the wrist as a measure of stiffness, ${ }^{5}$ they state that "elevations of resonant frequency (and therefore stiffness) have been observed in patients who are spastic following a stroke or who have Parkinson's disease" but report no further data. Others have developed methods for studying the viscoelastic properties of human limbs ${ }^{6-9}$ but none has attempted to answer the question of what role changes in passive elastic properties may play in Parkinsonian rigidity. 
Table 1 Clinical features of Parkinson's disease patients studied. Scale: $\pm=$ only by history (very infrequent); $1+=$ mild; $2+=$ moderate $3+=$ severe $;+=$ very severe.

\begin{tabular}{|c|c|c|c|c|c|c|c|c|c|}
\hline Patient & Sex & $\begin{array}{l}\text { Age } \\
(y r)\end{array}$ & $\begin{array}{l}\text { Stage } \\
\text { (Hoehn \& Yahr) }\end{array}$ & $\begin{array}{l}\text { Duration of } \\
P D(y r)\end{array}$ & Rigidity & Tremor & Bradykinesia & $\begin{array}{l}\text { Postural } \\
\text { imbalance }\end{array}$ & Therapy \\
\hline $\begin{array}{l}1 \\
2 \\
3\end{array}$ & $\begin{array}{l}\mathrm{F} \\
\mathrm{M} \\
\mathrm{F}\end{array}$ & $\begin{array}{l}66 \\
71 \\
56\end{array}$ & $\begin{array}{l}\text { III } \\
\text { II } \\
\text { I }\end{array}$ & $\begin{array}{r}10 \\
1 \\
2\end{array}$ & $\begin{array}{l}1+ \\
1-2+ \\
1+ \\
\quad \text { (R side) }\end{array}$ & $\begin{array}{l}1+ \\
\pm \\
1+ \\
\quad(\mathrm{R} \text { side })\end{array}$ & $\begin{array}{l}1+ \\
1+ \\
1+ \\
\quad \text { (R side) }\end{array}$ & $\begin{array}{l}1+ \\
0 \\
0\end{array}$ & $\begin{array}{l}\text { Sinemet } 25 / 2503 \text { tabs } / \mathrm{d} \\
\text { Sinemet } 25 / 1004 \text { tabs } / \mathrm{d} \\
\text { Artane } 3 \mathrm{mg} \text { QID }\end{array}$ \\
\hline $\begin{array}{l}4 \\
5\end{array}$ & $\begin{array}{l}\mathbf{F} \\
\mathbf{F}\end{array}$ & $\begin{array}{l}61 \\
75\end{array}$ & $\begin{array}{l}\text { III } \\
\text { III }\end{array}$ & $\begin{array}{r}3 \\
10\end{array}$ & $\begin{array}{l}1+ \\
1+\end{array}$ & \pm & $\begin{array}{l}1+ \\
1-2+\end{array}$ & $\begin{array}{l}2+ \\
1-2+\end{array}$ & $\begin{array}{l}\text { Sinemet } 25 / 1008 \mathrm{tabs} / \mathrm{d} \\
\text { Sinemet } 25 / 2506 \mathrm{tabs} / \mathrm{d} \text {; } \\
\text { Bromocriptine } 2 \cdot 5 \mathrm{mg} \text { TID }\end{array}$ \\
\hline 6 & $\mathbf{M}$ & 53 & III & 7 & $1+$ & $1+$ & $1+$ & $1+$ & Sinemet $25 / 2503.5 \mathrm{tabs} / \mathrm{d}$ \\
\hline $\begin{array}{r}7 \\
8 \\
9 \\
10\end{array}$ & $\begin{array}{l}\mathrm{M} \\
\mathrm{F} \\
\mathrm{F} \\
\mathrm{F}\end{array}$ & $\begin{array}{l}61 \\
57 \\
68 \\
63\end{array}$ & $\begin{array}{l}\text { III } \\
\text { III } \\
\text { II } \\
\text { III }\end{array}$ & $\begin{array}{r}2 \\
11 \\
4 \\
7\end{array}$ & $\begin{array}{l}1+ \\
1+ \\
1+ \\
1+\end{array}$ & $\begin{array}{l} \pm \\
\pm \\
1+ \\
1+\end{array}$ & $\begin{array}{l}1+ \\
1+ \\
1+ \\
1+\end{array}$ & $\begin{array}{l}2+ \\
1+ \\
0 \\
1+\end{array}$ & $\begin{array}{c}\text { Sinemet } 25 / 2503 \mathrm{tabs} / \mathrm{d} \\
\text { Sinemet } 10 / 1008 \mathrm{tabs} / \mathrm{d} \\
\text { Sinemet } 25 / 2503 \mathrm{tabs} / \mathrm{d} \\
\text { Sinemet } 25 / 1004 \mathrm{tabs} / \mathrm{d} \text {; } \\
\text { Artane } 2 \mathrm{mg} \text { TID }\end{array}$ \\
\hline 11 & $\mathbf{M}$ & 58 & III & 8 & $2+$ & $2+$ & $2+$ & $1+$ & $\begin{array}{l}\text { Sinemet } 25 / 2506 \text { tabs } / \mathrm{d} \text {; } \\
\text { Bromocriptine } 5 \mathrm{mg} \text { TID }\end{array}$ \\
\hline
\end{tabular}

\section{Methods}

Eleven patients with known Parkinson's disease completed the study after having been selected according to the following criteria: (1) mild rigidity in the right upper extremity (RUE), (2) lack of tremor in the RUE, and (3) mental competence and ability to voluntarily relax during the experiment. All but one of the patients were taking carbidopa/levodopa (Sinemet); one took trihexiphenidyl (Artane). Two took bromocriptine as well. There were four males and seven females, with a mean age of 62 years (range 53 to 75 ). All patients were examined by us prior to quantitative testing, and tone in the RUE was assessed clinically on a scale of $1+$ (mild) to $4+$ (very severe). The amount of time elapsed since the last dose of carbidopa/levodopa and other drugs was recorded. Each patient was staged according to the Hoehn and Yahr scale, ${ }^{10}$ (see table 1).

Stiffness in the RUE was measured quantitatively for each patient as described in our previous report. ${ }^{11}$ Triceps (and at times biceps, brachioradialis, or anconeous) EMG activity was monitored with surface electrodes. An additional two patients had been selected for the study but were excluded because of persistent EMG activity. The volume of the arm was estimated by modelling it as a cylinder. The circumference of the arm at three equidistant points between the shoulder and the elbow was measured, as was the length of the arm from the acromion to the lateral epicondyle of the humerus. After averaging the circumferences, the volume of the arm was calculated.

\section{Results}

The measured compliance $(\% / \mathrm{Nm})$ and stiffness ( $\mathrm{Nm} /$ radian) for each patient are shown in table 2 , along with calculated arm volumes. Also represented are clinical assessments of tone at the time of quantitative testing. At the bottom of the table are summed results from the Parkinson's disease patients and from normals for comparison (see the preceding report, ref 11).

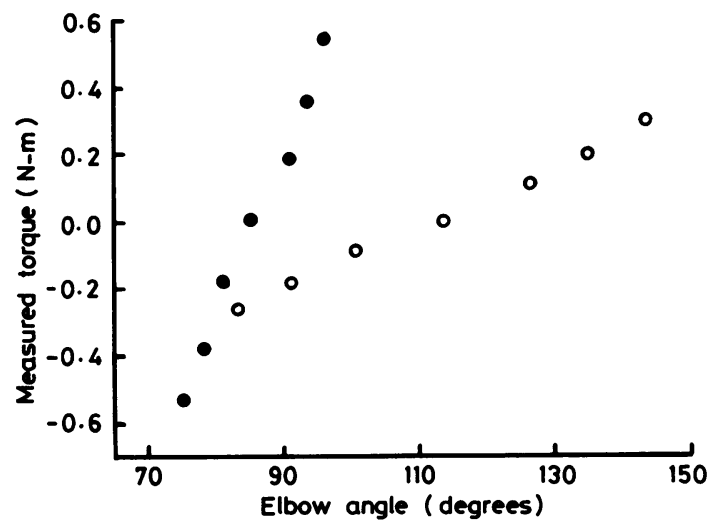

Fig 1 Angle-torque data from Subject 3 (open circles) and Subject 7 (filled circles). Data from Subject 3 are essentially linear over a range of $\pm 30^{\circ}$ from neutral position, as were data from control subjects. Data from Subject 7 were obtained over a more limited range of elbow angle because of increased stiffness.

Figure 1 demonstrates that when torque is plotted against angular displacement, the relationship is linear over a range of up to $\pm 30^{\circ}$ from the neutral angle, as in normal subjects. The slope of such a plot gives a single number which represents the stiffness for those conditions.

In Parkinsonian versus normal subjects, we observed that: (1) the neutral angle in Parkinson's disease patients was significantly smaller $\left(92^{\circ} \pm 15^{\circ}\right.$, $\mathrm{p}<0.02$, Mann-Whitney test $)$ than in normals $\left(107^{\circ}\right.$ $\pm 10^{\circ}$ ), and (2) in Parkinson's disease patients, even with relatively mild symptoms, the RUE was stiffer (range of compliance 14 to $110^{\circ} / \mathrm{Nm}$, mean $40 \pm 30 \mathrm{SD}$ ) than normals (range of compliance 32 to $145^{\circ} / \mathrm{Nm}$, mean $72 \pm 34 \mathrm{SD}$ ) in the totally relaxed 
Elastic properties of muscles measured at the elbow in man: II. Patients with Parkinsonian rigidity

Table 2 Results obtained from 11 individual Parkinson's disease patients. Mean values \pm S.D. for Parkinson's disease patients are compared to those of normal subjects (Wiegner and Watts, ${ }^{11}$ ) at the bottom

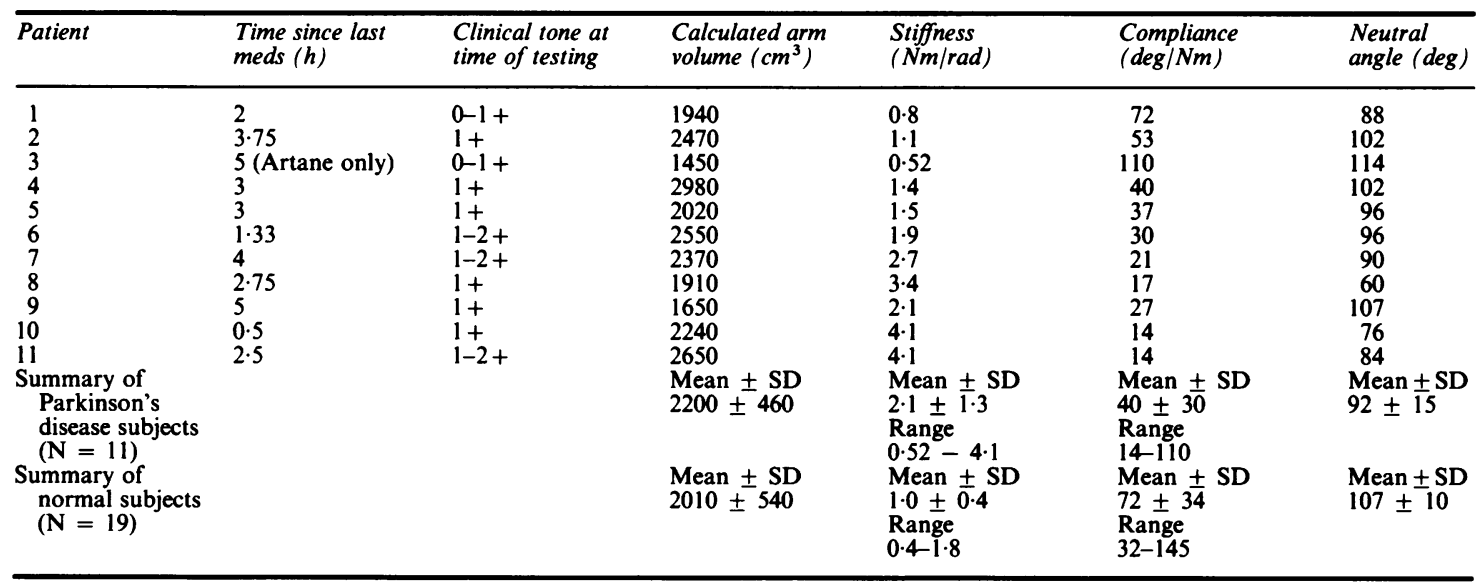

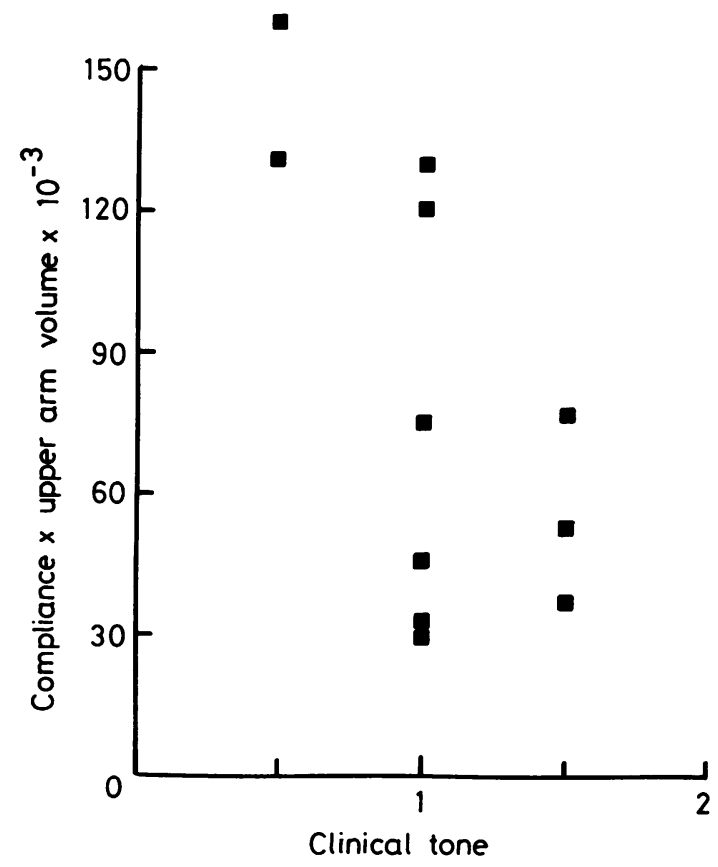

Fig 2 Relation between clinical assessment of tone at the elbow at the time of quantitative testing and elbow compliance corrected for arm volume in subjects with Parkinson's disease.

state with no electromyographic or voluntary activity present. Hence, this is a measure of passive stiffness, as best as we can determine. Figure 2 demonstrates that our quantitative measure of comptiance (multi=

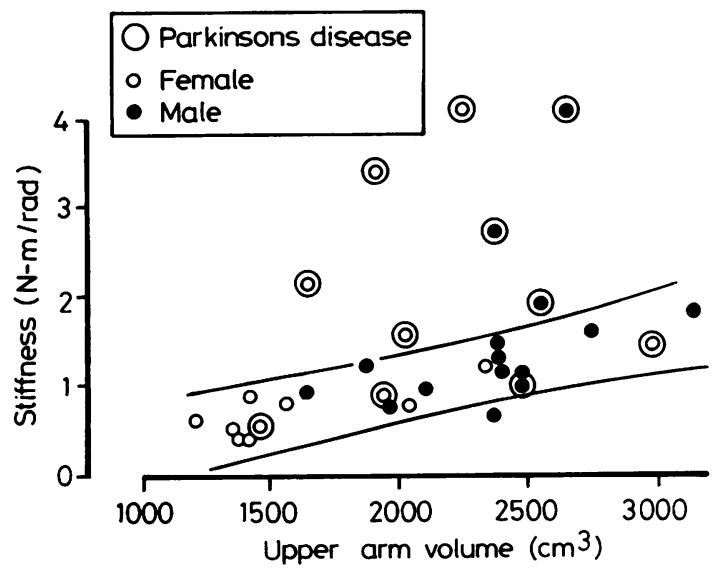

Fig 3 Plot of quantitative elbow stiffness versus upper arm volume for normal controls ( $\bigcirc$ or $\bigcirc$ not enclosed in circle) and Parkinson's disease subjects ( $\bigcirc$ or $\bigcirc$ enclosed in circle). The two lines represent $95 \%$ confidence limits for normal subjects. The majority of Parkinson's disease subjects fall well outside the normal range.

plied by upper arm volume in order to reduce scatter) was correlated with clinical assessment of tone, but it also shows the inaccuracy of such a clinical rating scale near the lower end of the range (that is, $1+$ ). Six patients were rated as having $1+$ rigidity, but there were fairly marked differences in their values of RUE compliance. Figure 3 shows that there was some correlation between stiffness and upper arm volume in Parkinson's disease patients, but it was much less striking than the correlation seen in normals. It is 
notable that seven of 11 Parkinson's disease patients clearly fall outside the "normal" range of stiffness corrected for upper arm volume.

\section{Discussion}

We have described a method for reproducibly measuring stiffness, and therefore tone, with a single number in the upper extremity of patients with Parkinson's disease. It is relatively simple given the proper equipment, and takes only about 30 minutes to complete. We applied it primarily in the passive state, but it can be used just as easily to measure stiffness in an upper limb with activated muscles (either voluntarily or by pathological processes). It may be used as an objective measure of tone to monitor therapy, as in drug trials or in the evaluation of response to physiotherapy, and would complement existing electrophysiological tests of tremor and timed performance tests which objectify bradykinesia. One can also follow the course of rigidity over time in an individual patient.

Our measurements of stiffness of muscles acting about the elbow in the relaxed, passive upper limb support the hypothesis that passive mechanical changes in the muscles or connective tissues may have taken place. The values of stiffness were higher in Parkinson's disease patients and the positive correlation with upper arm volume was less striking than in normals. It is of interest that the stiffness values (corrected for upper arm volume) of four of the patients fell within the "normal" range as determined in the preceding report ${ }^{11}$ (fig 3 ). A review of tables 1 and 2 reveals that these four patients (1-4) were in general the least affected clinically, and patients 2-4 had symptoms of only 1,2 and 3 years duration, respectively. The exception concerning duration of illness was Patient 1 , who despite having symptoms for 10 years had shown remarkably little progression of disease. Even though each of these patients was felt to have some degree of rigidity clinically, all four were rated at $1+$ which was the lowest value assignable. These observations are of potential pathophysiological importance in that duration and severity of "active" symptoms may be related to the development of changes in the passive mechanical properties of the limbs.

Stiffness was not correlated with age in normal subjects ${ }^{11}$ or in the patient group, nor was residual stiffness (after correction for arm volume) correlated with age. There was no gender-dependent difference in stiffness after the correction for arm volume, although this could be stated with more confidence if the subjec ${ }^{`}$ population had been much larger. Ordinary differences in adipose tissue/muscle mass ratios (which were not measured) do not appear to have played a role, with the possible exception of patient 4 . Patient 4 had a large amount of subcutaneous adipose tissue in the upper limb studied, and this caused her data point to be shifted far to the right in fig 3 . Her limb stiffness was, in fact, greater than any of the normal female subjects. In her case, correction of estimated arm volume by a triceps skinfold technique would have improved the accuracy of her assessment; we would recommend such a correction in future work.

Most previous studies of Parkinsonian rigidity $^{12-15}$ have dealt with the pathophysiology of only the neurally-mediated aspects of rigidity, with the exception of the work of Dietz, Berger and colleagues. ${ }^{16-18}$ In their electro-physiological studies of gait in spastic and rigid patients, they were led by their results to conclude that changes occurring in the passive mechanical properties of the lower limbs, "and not in the muscle activity itself, must be mainly responsible for the increased tone in both groups of patients." 16

The finding that the neutral angle is reduced in Parkinson's disease patients as compared to normals is consistent with the observed clinical fact that Parkinsonian patients tend to maintain their limbs and trunk in a flexed position. This occurs even in the relaxed, passive state and indeed our quantitative measurements confirm this. This would seem to imply that muscle and/or connective tissues in the limb have undergone some change which produces a new set of length-tension curves in the agonist and antagonist muscles acting about the elbow joint, causing a new neutral position. ${ }^{19-20}$

The cause of such changes in passive mechanical properties is unknown, but potential sources would include decreased use secondary to bradykinesia or perhaps prolonged activity related to neurallymediated rigidity which is more pronounced in flexors than extensors. This could then give rise to increased stiffness in the flexors, which could explain the present findings. Dietz et al $^{16}$ supposed that changes in the muscle fibres themselves and not the connective tissue are responsible for the muscle hypertonia based on their observations after altering the temperature surrounding the leg muscles. We have not performed measurements of stiffness after cooling the upper limb muscles in Parkinson's disease patients, hence we cannot support or refute their argument. More detailed anatomical and ultrastructural studies of the soft tissues of rigid and spastic limbs are needed to further answer this question.

Additional physiological studies, ideally in anaesthetised Parkinson's disease patients treated with neuromuscular blocking agents in preparation for surgery, are needed to elucidate further the roles played by changes in passive mechanical properties 
and neurally-mediated active processes in the production of Parkinsonian rigidity.

We appreciate the technical assistance of Ms Judith Warner and the secretarial assistance of Ms Betty AlAish and Ms Susan Wine.

This work was supported in part by the Massachusetts General Hospital Fund for the Study of Parkinson's Disease and Related Conditions. Dr Watts is currently a Medical Staff Fellow in the Laboratory of Neurophysiology, NIMH, Bethesda, MD, USA.

\section{References}

${ }^{1}$ Schwab RS. Problems in the clinical estimation of rigidity (hypertonia). Clin Pharmacol Ther 1964;5:942-6.

${ }^{2}$ Webster DD. A method of measuring the dynamic characteristics of muscle rigidity, stretch and tremor in the upper extremity. IRE Trans Med Electron 1959;ME-6:159-64.

${ }^{3}$ Webster DD. Rigidity in extrapyramidal disease. $J \mathrm{Neu}$ rosurg 1966;24 (Suppl II):299-307.

${ }^{4}$ Mortimer JA, Webster DD. Evidence for a quantitative association between EMG stretch responses and Parkinsonian rigidity. Brain Res 1979;162:169-73.

${ }^{5}$ Lakie M, Walsh EG, Wright GW. Resonance at the wrist demonstrated by the use of a torque motor: An instrumental analysis of muscle tone in man. $J$ Physiol (Lond) 1984;353:265-85.

${ }^{6}$ Hayes KC, Hatze H. Passive visco-elastic properties of the structures spanning the human elbow joint. Eur J Appl Physiol 1977;37:265-74.

${ }^{7}$ Nashold BS. An electronic method for measuring and recording resistance to passive muscle stretch. $J$ Neurosurg 1966;24 (Suppl II):310-4.

${ }^{8}$ Long CL, Thomas D, Crochetiere WJ. Objective measurement of muscle tone in the hand. Clin Pharm Ther 1964;5:909-17.
${ }^{9}$ Duggan TC, McLennan DL. Measurement of muscle tone: A method suitable for clinical use. EEG Clin Neurophysiol 1973;35:654-8.

${ }^{10}$ Hoehn MM, Yahr MD. Parkinsonism: Onset, progression, and mortality. Neurology 1967;17:427-42.

${ }^{11}$ Wiegner AW, Watts RL. Elastic properties of muscles measured at the elbow in man. I. Normal controls. $J$ Neurol Neurosurg Psychiatry (in press).

${ }^{12}$ Rushworth G. Spasticity and rigidity: an experimental study and review. J Neurol Neurosurg Psychiatry 1960;23:99-118.

${ }^{13}$ Rushworth G. The gamma system in Parkinsonism. Int $J$ Neurol 1961;2:34-50.

${ }^{14}$ Landau WM, Struppler A, Mehls O. A comparative electromyographic study of the reactions to passive movement in Parkinsonism and in normal subjects. Neurology 1966;16:34-48.

${ }^{15}$ Andrews CJ, Burke D, Lance JW. The response to muscle stretch and shortening in Parkinsonism rigidity. Brain 1972;95:795-812.

${ }^{16}$ Dietz V, Quintern J, Berger W. Electrophysiological studies of gait in spasticity and rigidity: evidence that altered mechanical properties of muscle contribute to hypertonia. Brain 1981;104:431-49.

${ }^{17}$ Dietz V, Berger W. Normal and impaired regulation of muscle stiffness in gait: a new hypothesis about muscle hypertonia. Exper Neurol 1983;79:680-7.

${ }^{18}$ Berger W, Horstmann G, Dietz V. Tension development and muscle activation in the leg during gait in spastic hemiparesis: independence of muscle hypertonia and exaggerated stretch reflexes. $J$ Neurol Neurosurg Psychiatry 1984;47:1029-33.

${ }^{19}$ Fel'dman AG. Functional tuning of the nervous system with control of movement or maintenance of a steady posture. II. Controllable parameters of the muscles. Biofizika 1966;11:498-508.

${ }^{20}$ Bizzi E, Accornero N, Chapple W, Hogan N. Arm trajectory formation in monkeys. Exp Brain Res 1982;46:139-43. 